\title{
Assessment of the Bioavailability of $\mathrm{Cu}, \mathrm{Pb}$, and $\mathrm{Zn}$ through Petunia axillaris in Contaminated Soils
}

\author{
Lydia Bondareva, ${ }^{1}$ Roman Teisserenc, ${ }^{2}$ Nina Pakharkova, ${ }^{1}$ Alexander Shubin, ${ }^{1}$ \\ Théo Le Dantec, ${ }^{2}$ Leïla Renon, ${ }^{2}$ and Ivan Svoboda ${ }^{1}$ \\ ${ }^{1}$ Siberian Federal University, Svobodny Prospect 79, Krasnoyarsk 660041, Russia \\ ${ }^{2}$ INP-ENSAT, Toulouse, France \\ Correspondence should be addressed to Lydia Bondareva; lydiabondareva@gmail.com
}

Received 28 February 2014; Revised 5 August 2014; Accepted 5 August 2014; Published 25 August 2014

Academic Editor: Pavlos Kassomenos

Copyright (C) 2014 Lydia Bondareva et al. This is an open access article distributed under the Creative Commons Attribution License, which permits unrestricted use, distribution, and reproduction in any medium, provided the original work is properly cited.

\begin{abstract}
Heavy metals are potentially toxic to human life and the environment. Metal toxicity depends on chemical associations in soils. For this reason, determining the chemical form of a metal in soils is important to evaluate its mobility and the potential accumulation. The aim of this examination is to evaluate the accumulation potential of Petunia $x$ hybrida as a flower crop for three metals, namely, copper $(\mathrm{Cu})$, lead $(\mathrm{Pb})$, and nickel $(\mathrm{Ni})$. Trace metals $(\mathrm{Zn}, \mathrm{Cu}$, and $\mathrm{Pb})$ in the soils were partitioned by a sequential extraction procedure into $\mathrm{H}_{2} \mathrm{O}$ extractable ( $\left.\mathrm{F} 1\right), 1 \mathrm{M} \mathrm{CH}_{3} \mathrm{COONa}$ extractable (F2). Chemical fractionation showed that $\mathrm{F}$ 1 and $\mathrm{F} 2$ fraction of the metals were near $1 \%$ and residue was the dominant form for $\mathrm{Zn}, \mathrm{Cu}$, and $\mathrm{Pb}$ in all samples. Using fluorescence method allowed us to estimate condition of the plants by adding metals. As result of plant and soil analysis, we can conclude that Petunia has Cu, $\mathrm{Zn}$, and Ni tolerance and accumulation. Therefore, Petunia has the potential to serve as a model species for developing herbaceous, ornamental plants for phytoremediation.
\end{abstract}

\section{Introduction}

Russia is one of the biggest country of the world, ranked second among the five biggest mining countries, behind South Africa [1]. Its mining richness is too large to be entirely quoted, but, for example, in 2009, Russia was leading the world in diamond, nickel, and palladium production, and ranked second for aluminum, platinum, and zirconium [2]. The copper production associated with nickel extraction is eliminate, therefore, significant as Russia is the seventh country in the world with 710,000 Tons [3]. Not only is the soil a source of nutrients for plant growth, but also it acts as a sink for contaminants from industrial and agricultural waste materials $[4,5]$.

The accumulation of heavy metals in environmental samples represents a potential risk to human health due to the transfer of these elements to aquatic media, their uptake by plants, and their subsequent introduction into the food chain. The toxicity, bioavailability, and mobility of metals are related to their species $[6,7]$. However, the determination of chemical species is difficult and sometimes impossible. Therefore, the use of sequential extraction procedures for environmental studies provides an important tool for the determination of the different chemical forms or ways of binding between trace metals and soil components [8]. Chemical extraction is eliminate employed to assess operationally defined metal fractions, which can be related to chemical species, as well as to potentially mobile, bioavailable or ecotoxic phases of a sample. It is generally accepted that the ecological effects of metals (e.g., their bioavailability, ecotoxicology and risk of groundwater contamination) are related to such mobile fractions rather than to the total concentration [9].

The results of speciation studies on solution suggest that metals from anthropogenic sources are mainly in bioavailable forms [10]. The observed trend of the proportion of bioavailability heavy metals at the model systems $(\mathrm{Pb} \approx \mathrm{Cu} \approx \mathrm{Zn})$ is confirmed by other researchers for Quercus ilex [11], for Petunia. Copper and $\mathrm{Zn}$ are present as water-soluble salts [12] 
and it is generally reported that the leaching of each metal is related to the kinds of liaisons between metals and the solid matrix [13].

The experiment is focused on the study of three metals, namely, copper $(\mathrm{Cu})$, zinc $(\mathrm{Zn})$, and lead $(\mathrm{Pb})$. The aim is to evaluate the study of the bioavailability of $\mathrm{Cu}, \mathrm{Zn}$, and $\mathrm{Pb}$ for Petunia $x$ hybrida as a flower crop. Therefore, an experimental setup was made to observe in laboratory conditions the plant uptake of each metal and translocation areas of these metals.

\section{Material and Methods}

2.1. Soil Sampling. The soil samples were taken in two different agricultural fields in the Krasnoyarsk region. This type of a substrate was chosen since the agriculture is a vital activity and the soil quality is a decisive factor. In what follows the mention of same samples of soils from deferent places around of Krasnoyarsk city will be made.

The soil cores were contained in a $6.0 \mathrm{~cm}$ diameter plastic sleeve that was capped on both ends. The sampling method consists in taking the soil from the ground surface of a $1 \mathrm{~m}^{2}$ plot. The soils were characterized as Humod [14] consisting of a thick sequence of well-drained horizons consisting of a thin 0 horizon $(0$ to $10 \mathrm{~cm})$. The soil types at the 1 contain textures that are predominately silt loams, silty clay loams, and clay loams. The soil types at the 2 included alluvium, sandstone, shale, and limestone.

2.2. Greenhouse Experiment. Petunia $x$ hybrida is mainly reproduced by seeds germinating in 5-15 days, with the optimal germination and growth temperature ranging from $20^{\circ} \mathrm{C}$ to $26^{\circ} \mathrm{C}[15,16]$. It is tolerant to relatively severe conditions and hot climate and needs at least five hours of sunlight a day. Petunia can easily be cultivated in hanging baskets.

\subsection{Experimental Procedure. Four plastic boxes were used} for each soil sample: a control one and the other three with metal solutions. The content of the added metal was $\mathrm{Cu}^{2+}-5,15$, and $30 \mathrm{mg} / \mathrm{kg}, \mathrm{Pb}^{2+}-2,5$, and $10 \mathrm{mg} / \mathrm{kg}$, and $\mathrm{Zn}^{2+}-115,150$, and $200 \mathrm{mg} / \mathrm{kg}$. Then, the soil samples were homogenized by stirring and distilled water was added until certain moisture was achieved. After 24 hours two samples of Petunia $x$ hybrida in bloom were planted in a separate container, with one specimen left as a control one for the analysis. The experiments lasted for 30 days at the natural day and night (16/8 day/night) and at room temperature (near $\left.25^{\circ} \mathrm{C}\right)$.

\subsection{Analytical Methods}

2.4.1. Plants. Roots, stems, and leaves of the all background plants were separated and weighed. Then, they were dried in a drier at $45^{\circ} \mathrm{C}$ during $24 \mathrm{~h}$.

2.4.2. Sequential Extractions of Soil. The total weight of the samples taken was $2 \mathrm{~kg}$. Immediately after sampling the whole amount of the substance was sieved with the mesh diameter being $50 \mu \mathrm{m}$ and divided into several portions with the weight approximately $1 \mathrm{~kg}$. Each portion was packed into a plastic bag and placed into a fridge. Just before carrying out sequential chemical fractionation the soils from the bags were thoroughly mixed. From the whole amount the portions having $80 \mathrm{~g}$ of wet weight were taken. For each fractionation Scheme 3 portions were selected.

The spread scheme of sequential chemical fractionation was used in the work. This is fractionation developed on the basis of the Tessier technique $[17,18]$.

According to the sequential extraction procedure operationally groups heavy metals into the following two fractions.

(F1) Water Soluble Fraction. $5 \mathrm{~g}$ soil sample mixed in $50 \mathrm{~mL}$ of distilled water was filtered to estimate the water-soluble metal fraction and shaking for $24 \mathrm{~h}$ at $20^{\circ} \mathrm{C}$ was done. Then, the residue on the filter was prepared for the AAA and the filtrate was analyzed by ICP-MS to determine its metal content.

(F2) Exchangeable Fraction. $2 \mathrm{~g}$ soil sample mixed in $20 \mathrm{~mL}$ of $1 \mathrm{M}$ ammonium acetate $\left(\mathrm{CH}_{3} \mathrm{COONH}_{4}\right)$ and shaking for $1 \mathrm{~h}$ at $20^{\circ} \mathrm{C}$ was done. As in the above case, the residue on the filter was prepared for the AAA and the filtrate-for ICP-MS.

A study of the phytotoxic effect was carried out by the fluorimeter Photon-10 on living plants, immediately after removing them from the experimental systems.

2.4.3. Soil Texture Mechanical Analysis. The ground sample was pressed into tablets with diameter $6 \mathrm{~mm}$ and mass $30 \mathrm{mg}$ and subjected to synchrotron radiation X-ray fluorescence analysis (SXRF). Soil texture analysis was performed using the pipette method [19] after the destruction of organic matter with hydrogen peroxide (35\%).

The silicate composition of sediment samples was determined using a VRA-20R X-ray phase analyzer. For all determined elements detection limits were $0.02-0.005 \%$. Concentrations were calculated using the fundamental parameter method [20]. Standard reference material was Lake Baikal sediment BIL-1. The relative standard deviation in determination of concentrations of the elements listed above was 10$15 \%$.

The morphology and material composition of total soil particles, the sand fraction, and heavy minerals of the sand fraction were examined using the electron scanning microscope TM-1000 (Hitachi, Japan), with the X-ray spectral energy-dispersive analyzer SwiftED (Oxford Instrument Analytical, England) when registering in back-scattered electrons with the accelerating power of $15 \mathrm{~kW}$ in the low vacuum regime. The soil particles were directly fixed on the filters by a double-sided adhesive conductive carbon tape on the sample mount and were placed into the chamber of the electron microscope. Micrographs scanned in back-scattered electrons were collected into a separate file and were subjected to standard digital processing to increase the image sharpness and contrast. Spectral analysis of some parts of the sample (selected particles, characteristic details) was made.

2.4.4. Heavy Metals Determination in Soil and Plant Samples. Aqua-regia mixture, $25 \mathrm{~mL}$ (70\% high purity $\mathrm{HNO}_{3}$ and $\mathrm{HCl}$ ratio $3: 1$ and $5 \mathrm{~mL} 30 \% \mathrm{H}_{2} \mathrm{O}_{2}$ ), was added to an empty 
$100 \mathrm{~mL}$ beaker with plants or soils and heated at $80^{\circ} \mathrm{C}$ till the solution became cleared [21]. Determination of the heavy metals such as $\mathrm{Cu}, \mathrm{Pb}$, and $\mathrm{Zn}$ in the filtrate of vegetables and blanks was achieved by atomic absorption spectrometer, Solaar M6, Thermo Electron Corp. (USA). The instrument was calibrated using manually prepared standard solution of respective heavy metals. An analytical grade of a nitrate salt of $\mathrm{Pb}$ and granules of $\mathrm{Cu}$ and $\mathrm{Zn}$ were used in the preparations of solutions used in the spiking of samples for $\mathrm{Pb}, \mathrm{Cu}$, and $\mathrm{Zn}$. Acetylene gas was used as the fuel and air as the support. An oxidizing flame was used in all cases.

ICP-MS (inductively coupled plasma mass spectrometer) $\mathrm{X}$ Series 2, Thermo Scientific Corp. (USA) is used for the sensitive determination of trace elements in digested solution of solid samples.

2.4.5. Fluorimetry. The registration of delayed chlorophyll fluorescence was performed using the computerized fluorimeter "Photon-10." This device is intended for registration of several delayed and variable fluorescence parameters of different plant objects (chloroplasts, algae, plant leaves, and lichens). In this device the patented method of rapid assessment of chemical substances phytotoxic effect based on the registration of delayed chlorophyll fluorescence relational index is implemented [22].

2.4.6. Quality Assurance. Blanks and source of quality control standards were measured at every five samples to detect contamination and drift. The elemental concentrations of procedural blanks were generally $<5 \%$ of the mean analyte concentrations for all the metals. Precision and accuracy of analysis were ensured through replicate analysis of the samples; acceptable percentage recoveries $(86.5 \% \pm 0.005$ to $96.4 \pm 0.003)$ were obtained from spiked digested vegetable samples.

\section{Results and Discussion}

3.1. Soil Analysis. In the initial soil samples were analyzed to examine their grain-size, mineral, and elemental composition. The analyzed samples contained considerable amounts of organic matter. The organic matter was mainly represented by fine dark-brown detritus and contained considerable amounts of humic substances [23]. Organic particles adhere to particles of clay minerals and sand. Therefore, to separate the clay fraction, we increased the soaking time and the number of stirrings. Organics was successfully removed by heating the samples at $480^{\circ} \mathrm{C}$, but the structure of clay particles had changed considerably.

The major fractions of the inorganic component of the soil were fine sand $(0.25-0.05 \mathrm{~mm})$, fine-grained siltstone $(0.05-0.005 \mathrm{~mm})$, and fine mineral powder $(<0.005 \mathrm{~mm})$. The $0.004-0.005 \mathrm{~mm}$ size range can include both the smallest of the grains and the largest of the powder particles. The major grain-size fraction of the sediments was fine-grained siltstone: $58 \%$ to $90 \%$. The clay fraction made up just $~ 3 \%$.

Common layered materials of significance in materials applications include clay minerals and layered double

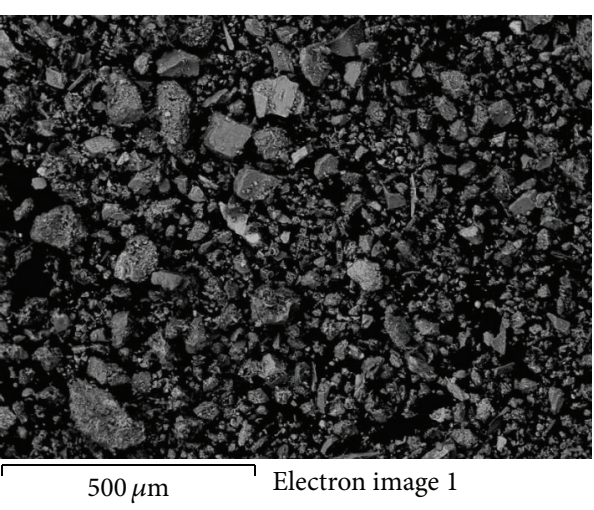

FIGURE 1: General view of the soil samples.

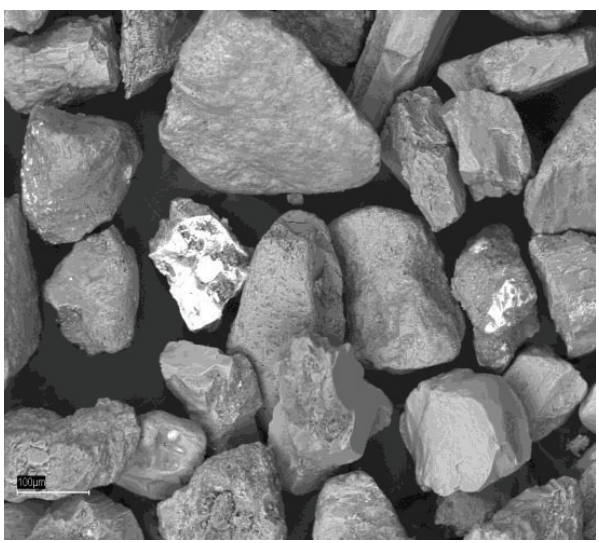

FIGURE 2: General view of the rudaceous fraction of the soil samples.

hydroxide compounds. In general, clay minerals are comprised of multiple layers of hydroxylated and coordinated tetrahedral and octahedral sheets. Detailed examination of the fraction composition of the fine mineral powder showed the predominance of $0.5-\mu \mathrm{m}$ to $1.5-\mu \mathrm{m}$ particles. The analysis of the obtained data also suggested that mineral particles were subjected to dispersion and amorphization, resulting in a considerable increase in the content of X-ray amorphous particles of sizes less than $0.1 \mu \mathrm{m}$.

The qualitative analysis of separate fragments included into the composition of the soils has been made by the sinchrotron radiation $\mathrm{X}$-ray fluorescence analysis. The results are presented in Figures 1 and 2.

The material composition of the of coarsely ground fraction fragments for the soils under study has been analyzed, that is, after the elimination of clay minerals and organic substances. Considerable differences in the elemental composition of the genetic fragments being compared can, mainly, be caused by the difference in the nature of the considered particle origin. The obtained results show that in spite of careful sample preparation for the analysis, it is impossible to achieve the sample homogeneity as a whole. The particles under study are of different origin, leading to significant differences in the granularity, chemical structure, and porosity of a particle (of its surface) and so forth. This does not 
TABLE 1: Content of some macronutrients in soil samples.

\begin{tabular}{lccccc}
\hline \multirow{2}{*}{ Sample } & \multicolumn{5}{c}{ Elements, \% } \\
& $\mathrm{K}$ & $\mathrm{Ca}$ & $\mathrm{Ti}$ & $\mathrm{Mn}$ & $\mathrm{Fe}$ \\
\hline 1 & $1.7 \pm 0.2$ & $2.3 \pm 0.1$ & $0.58 \pm 0.05$ & $0.07 \pm 0.01$ & $4.10 \pm 0.08$ \\
2 & $1.8 \pm 0.3$ & $2.6 \pm 0.2$ & $0.49 \pm 0.03$ & $0.07 \pm 0.02$ & $3.52 \pm 0.06$ \\
\hline
\end{tabular}

Data are mean $\pm \mathrm{SD}, n=3$.

contradict to the earlier data on geochemical composition and physicochemical properties of the soils [24-26].

The change of the macronutrients content is not considerable (Table 1).

The change of micronutrients content can contribute to the distribution of pollutions between migrating (water solubility and exchangeable fractions) and undissolved forms in the soils (Table 2).

Such nonuniform distribution of microelements between the samples of soils sampled in one area is likely to be connected with the following [24].

(1) Inhomogenuity of the rock, resulting in

(2) absolute accumulation or release of elements due to the transfer of their compounds in the geologic profile and (or)

(3) Relative accumulation (release) of elements due to the release (accumulation) of other chemical substances in the given sample.

The water solubility and exchangeable fractions, corresponding to the first two fractions, are generally called "bioavailable," as they exhibit mobility relative to the environment and are potentially available for plants.

We found increasing amount of available metal plants for water-soluble and exchangeable fractions of the soils 1 and 2, where the metals are located in the most accessible way for the plants (Table 3 ).

Trace metals $(\mathrm{Zn}, \mathrm{Cu}$, and $\mathrm{Pb})$ in the soils were partitioned by a sequential extraction procedure into $\mathrm{H}_{2} \mathrm{O}$ extractable (F1), $1 \mathrm{M} \mathrm{CH}_{3} \mathrm{COONa}$ extractable (F2). Chemical fractionation showed that F1 and F2 fraction of the metals was near 1\% and residual form was the dominant for $\mathrm{Zn}, \mathrm{Cu}$, and $\mathrm{Pb}$ in all samples.

After experiments we found what distribution of $\mathrm{Cu}, \mathrm{Zn}$, and $\mathrm{Pb}$ in water soluble and exchangeable fractions were the following. Chemical fractionation showed that F1 and F2 fraction of the metals were near $95 \%$ from added $\mathrm{Zn}, \mathrm{Cu}$, and $\mathrm{Pb}$ in the investigation samples of soil.

In soil medium, sorption/desorption reactions as well as chemical complexation with inorganic and organic ligands and redox reactions, both biotic and abiotic, influence bioavailability, leaching, and toxicity of metals. These reactions are affected by many factors such as $\mathrm{pH}$, nature of sorbents, presence and concentration of organic and inorganic ligands, including humic and fulvic acids, root exudates, microbial metabolites, and nutrients [23,27].

3.2. Plants Analysis. The average values of the application effects, which were accepted as significant according to

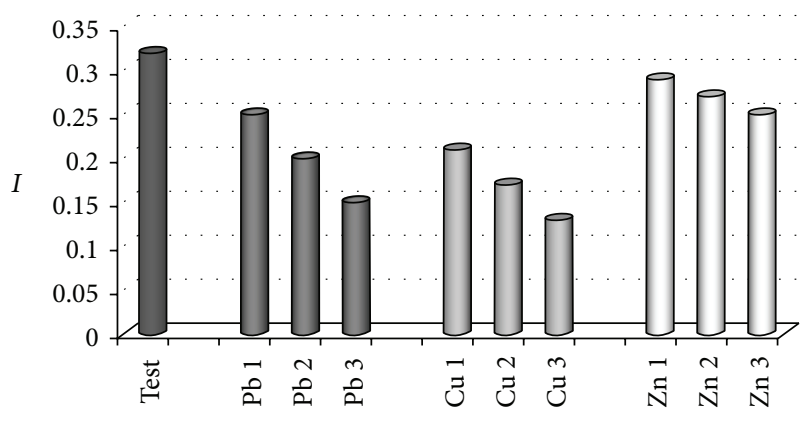

Figure 3: The dependence of the fluorescence on the type of metal ( $\mathrm{Pb}, \mathrm{Cu}$, and $\mathrm{Zn}) .1,2,3$ experimental samples with different concentrations of metals.

analysis of variance, are shown in Table 4 for plant species. Concentrations $\mathrm{Pb}$ in the tissues of Petunia $x$ hybrida decreased from root to stems.

Copper is an important pollutant that originates from sludge and manure application [27, 28]. When the uptake of copper by plants was examined, the highest value was obtained for Petunia $x$ hybrida root $42.58 \pm 7.99 \mathrm{mg} \cdot \mathrm{kg}^{-1}$ (mean \pm standard deviation) from Soil 2.

Petunia $x$ hybrida absorbed $\mathrm{Zn}$ in its roots in Soil 1 $\left(68.33 \pm 7.60 \mathrm{mg} \cdot \mathrm{kg}^{-1}\right)$ two times more than in Soil $2(32.58 \pm$ $\left.8.23 \mathrm{mg} \cdot \mathrm{kg}^{-1}\right)$.

Several studies demonstrated that metal concentration in the plant tissue was a fraction of the heavy metal content in the growing environment. It has been well documented that the accumulation of metals was more in lower part of the plant grown on contaminated soil than in upper part. The root tissues accumulate significantly greater concentrations of metals than shoots, indicating high plant availability of the substrate metals as well as its limited mobility once inside the plant. This is consistent with previous observations. All of the plant roots accumulate significantly greater concentrations of metals than stems in this study.

When using delayed fluorescence of chlorophyll in leaves of petunia, we found the following. Despite the fact that all plants apparently did not differ from each other, the most toxic effects we found in the system with copper and lead salts (Figure 3).

Delayed fluorescence intensity depends on the rate of photosynthesis, so the more the damage to plants, the lower the intensity of delayed fluorescence.

The variations in the concentrations of the heavy metals in plants may be ascribed to the heavy metals concentrations of soil, air, and irrigation water of their production sites and also the absorption of heavy metals from aerial depositions during transportation and marketing.

Foliage analysis has often been used in heavy metal biomonitoring studies and concurrent analysis of unwashed and washed plants allows external composition to be distinguished from internal [29]. The differences between unwashed and washed plants with regard to the heavy metal concentrations suggest that heavy metals reach stems and leaves by flow substances. 
TABLE 2: Content of some micronutrients in soil samples.

\begin{tabular}{|c|c|c|c|c|c|c|c|c|c|}
\hline \multirow{2}{*}{ Sample } & \multicolumn{9}{|c|}{ Elements, $\mu \mathrm{g} / \mathrm{kg}$. } \\
\hline & $\mathrm{V}$ & $\mathrm{Cr}$ & $\mathrm{Ni}$ & $\mathrm{Cu}$ & $\mathrm{Zn}$ & $\mathrm{Rb}$ & $\mathrm{Sr}$ & $\mathrm{Y}$ & $\mathrm{Zr}$ \\
\hline 1 & $85 \pm 9$ & $102 \pm 2$ & $70 \pm 8$ & $55 \pm 3$ & $197 \pm 7$ & $68 \pm 4$ & $334 \pm 8$ & $30 \pm 4$ & $191 \pm 12$ \\
\hline 2 & $103 \pm 11$ & $129 \pm 9$ & $58 \pm 5$ & $32 \pm 6$ & $153 \pm 12$ & $61 \pm 4$ & $381 \pm 20$ & $26 \pm 3$ & $231 \pm 14$ \\
\hline
\end{tabular}

Data are mean $\pm \mathrm{SD}, n=3$.

TABLE 3: The content of $\mathrm{Cu}, \mathrm{Ni}$, and $\mathrm{Zn}$ in soils 1 and 2, determined by ICP-MS after the extraction using water and ammonium acetate (RSD $=5 \%)$.

\begin{tabular}{|c|c|c|c|c|c|c|c|c|c|}
\hline \multirow{2}{*}{ Bulk } & \multicolumn{3}{|c|}{$\mathrm{Pb}, \mu \mathrm{g}$} & \multicolumn{3}{|c|}{$\mathrm{Cu}, \mu \mathrm{g}$} & \multicolumn{3}{|c|}{$\mathrm{Zn}, \mu \mathrm{g}$} \\
\hline & 1 & 2 & 3 & 1 & 2 & 3 & 1 & 2 & 3 \\
\hline \multicolumn{10}{|c|}{ Water-soluble fraction } \\
\hline Soil 1 & 0.9 & 1.5 & 2.4 & 1.4 & 2.1 & 3.4 & 3.8 & 4.4 & 6.2 \\
\hline Soil 2 & 0.5 & 0.7 & 1.0 & 0.8 & 1.1 & 1.7 & 1.2 & 1.8 & 2.7 \\
\hline \multicolumn{10}{|c|}{ Exchangeable fraction } \\
\hline Soil 1 & 0.2 & 0.5 & 0.8 & 0.4 & 0.7 & 1.1 & 0.1 & 0.5 & 0.7 \\
\hline Soil 2 & 1.2 & 1.6 & 2.0 & 0.7 & 1.0 & 1.2 & 1.8 & 2.4 & 3.2 \\
\hline
\end{tabular}

1, 2, 3 experimental samples with different concentrations of metals; all values are means of 5 replications.

TABLE 4: Heavy metal accumulation in Petunia $x$ hybrida.

\begin{tabular}{|c|c|c|c|c|c|c|c|c|c|c|}
\hline \multirow{3}{*}{ Plant part } & \multirow{3}{*}{ Soil } & \multicolumn{9}{|c|}{ Metal in plants $\left(\mathrm{mg} \cdot \mathrm{kg}^{-1}\right)$} \\
\hline & & \multicolumn{3}{|c|}{$\mathrm{Pb}$} & \multicolumn{3}{|c|}{$\mathrm{Cu}$} & \multicolumn{3}{|c|}{$\mathrm{Zn}$} \\
\hline & & 1 & 2 & 3 & 1 & 2 & 3 & 1 & 2 & 3 \\
\hline Root & 1 & $9 \pm 7$ & $15 \pm 8$ & $20 \pm 9$ & $14 \pm 4$ & $27 \pm 11$ & $27 \pm 14$ & $30 \pm 20$ & $32 \pm 28$ & $66 \pm 8$ \\
\hline Stem & 1 & $6 \pm 2$ & $6 \pm 3$ & $8 \pm 5$ & $6 \pm 2$ & $8 \pm 2$ & $12 \pm 6$ & $3 \pm 1$ & $17 \pm 16$ & $27 \pm 23$ \\
\hline Root & 2 & $10 \pm 6$ & $21 \pm 11$ & $26 \pm 16$ & $16 \pm 4$ & $24 \pm 6$ & $43 \pm 8$ & $12 \pm 8$ & $19 \pm 13$ & $33 \pm 8$ \\
\hline Stem & 2 & $6 \pm 3$ & $9 \pm 5$ & $10 \pm 3$ & $9 \pm 2$ & $10 \pm 4$ & $14 \pm 3$ & $5 \pm 4$ & $6 \pm 5$ & $9 \pm 7$ \\
\hline
\end{tabular}

Data are mean $\pm \mathrm{SD}, n=5$.

In literature the results are often specific to soil, metal, and plant; and there is almost no standard information on the subject. Moreover, there are hardly any papers on the phytoremediation abilities of Petunia $x$ hybrida, in particular. Some studies have been conducted on genetically modified Tobacco [30] which belongs the Solanacea family, such as Petunia. The results show the ability of accumulating $\mathrm{Pb}$ and, in less extent, $\mathrm{Zn}$. The metals such as $\mathrm{Pb}, \mathrm{Zn}$, and $\mathrm{Cu}$ are the best candidates for removal by phytoextraction because the majority of approximately 400 known plants absorbing unusually large amounts of metals are likely to accumulate these metals [31].

\section{Conclusion}

Petunia $x$ hybrida is effective plants for possible remediation treatment; some contaminated and spoilt landscapes can be recovered. Sewage sludge which is serious pollution problem all over the world could be used as media for green landscapes and this can be achieved using Petunia $x$ Hybrida. This study strongly supports that the production of sewage sludge compost represents a good way to produce a dry, nutrientrich, stabilized, and easy to transport fertilizer that can be applied to horticultural plots. Metal flux through consuming interfaces in ligand mixtures: boundary conditions do not influence the lability and relative contributions of metal species.

\section{Conflict of Interests}

The authors declare that there is no conflict of interests regarding the publication of this paper.

\section{Acknowledgment}

This work is performed under partial financial support of the State subsidy.

\section{References}

[1] C. O'Donnell, “The World's Top 5 Mining Countries," Consulté le August 16, 2012, sur Wealth Wire, 2011, http://www.wealthwire.com/news/global/2372.

[2] Info Mine Research Group, "Mining in Russia. Consulté le August 15, 2012. sur Country Mine," http://www.infomine.com/ countries/russia.asp.

[3] "United States Geological Survey, World Nickel Producing Countries," Consulté le August 2012, sur Maps of World, 2012.

[4] N. T. Basta, J. A. Ryan, and R. L. Chaney, "Trace element chemistry in residual-treated soil: key concepts and metal 
bioavailability," Journal of Environmental Quality, vol. 34, no. 1, pp. 49-63, 2005.

[5] N. S. Bolan, D. C. Adriano, R. Natesan, and B. J. Koo, "Effects of organic amendments on the reduction and phytoavailability of chromate in mineral soil," Journal of Environmental Quality, vol. 32, no. 1, pp. 120-128, 2003.

[6] R. A. Goyer, C. D. Klaassen, and M. P. Waalkes, Eds., Metal Toxicology, Academic Press, San Diego, Calif, USA, 1995.

[7] C. D. Klaassen and D. L. Eaton, "Principles of toxicology," in Casarett and Doull's Toxicology: The Basic Science of Poisons, M. O. Amdur, J. Doull, and C. D. Klaassen, Eds., pp. 12-49, Pergamon Press, New York, NY, USA, 1991.

[8] I. Ahumada, J. Mendoza, E. Navarrete, and L. Ascar, "Sequential extraction of heavy metals in soils irrigated with wastewater," Communications in Soil Science and Plant Analysis, vol. 30, no. 9-10, pp. 1507-1519, 1999.

[9] P. H. Quevauviller, Ed., Methodologies in Soil and Sediment Fractionation Studies, Royal Society of Chemistry, Great Britain, UK, 2002.

[10] A. J. F. Espinosa, M. T. Rodríguez, F. J. B. de La Rosa, and J. C. J. Sánchez, "A chemical speciation of trace metals for fine urban particles," Atmospheric Environment, vol. 36, no. 5, pp. 773-780, 2002.

[11] F. de Nicola, G. Maisto, M. V. Prati, and A. Alfani, "Leaf accumulation of trace elements and polycyclic aromatic hydrocarbons (PAHs) in Quercus ilex L.," Environmental Pollution, vol. 153, no. 2, pp. 376-383, 2008.

[12] J. Caselles, C. Colliga, and P. Zornoza, "Evaluation of trace element pollution from vehicle emissions in petunia plants," Water, Air, and Soil Pollution, vol. 136, no. 1-4, pp. 1-9, 2002.

[13] M. R. Heal, L. R. Hibbs, R. M. Agius, and I. J. Beverland, “Total and water-soluble trace metal content of urban background PM 10, PM2.5 and black smoke in Edinburgh, UK," Atmospheric Environment, vol. 39, no. 8, pp. 1417-1430, 2005.

[14] Soil Survey Staff, Keys to Soil Taxonomy, USDA-NRCS, Washington, DC, USA, 8th edition, 1998.

[15] T. Gerats and M. Vandenbussche, "A model system for comparative research: petunia," Trends in Plant Science, vol. 10, no. 5, pp. 251-256, 2005.

[16] M. Dole John and H. F. Wilkins, Floriculture: Principles and Species, Pearson/Prentice Hall, Upper Saddle River, NJ, USA, 2nd edition, 2005.

[17] L. G. Bondareva and A. Y. Bolsunovskii, "Speciation of artificial radionuclides $60 \mathrm{Co}, 137 \mathrm{Cs}, 152 \mathrm{Eu}$, and $241 \mathrm{Am}$ in bottom sediments of the Yenisei River," Radiochemistry, vol. 50, no. 5, pp. 547-552, 2008.

[18] A. Tessier, P. G. C. Campbell, and M. Blsson, "Sequential extraction procedure for the speciation of particulate trace metals," Analytical Chemistry, vol. 51, no. 7, pp. 844-851, 1979.

[19] G. W. Gee and J. W. Bauder, "Particle size analysis by hydrometer: a simplified method for routine textural analysis and a sensitivity test of measurement parameters," Soil Science Society of America Journal, vol. 43, no. 5, pp. 1004-1007, 1979.

[20] V. P. Afonin, T. N. Gunicheva, and L. F. Piskunova, X-Ray Fluorescence Silicate Analysis, Nauka, Novosibirsk, Russia, 1984, (Russian).

[21] M. R. Flores and E. R. Castellon, "Lead and cadmium levels in soil and plants near highways and their correlation with traffic density," Environmental Pollution B: Chemical and Physical, vol. 4, no. 4, pp. 281-290, 1982.
[22] Y. S. Grigor'ev, E. A. Furyaev, and A. A. Andreev, RF Patent no. 2069851, Byull. Izobret. no. 33, 1996 (Russian).

[23] L. Bondareva, "The relationship of mineral and geochemical composition to artificial radionuclide partitioning in Yenisei river sediments downstream from Krasnoyarsk," Environmental Monitoring and Assessment, vol. 184, no. 6, pp. 3831-3847, 2012.

[24] D. S. Orlov, L. K. Sadovnikova, and N. I. Sukhanova, Khimiya Pochv (Soil Chemistry), Vysshaya Shkola, Moscow, Russia, 2005, (Russian).

[25] R. M. Garrels and C. L. Christ, Solutions, Minerals, and Equilibria, Harper \& Row, 1995.

[26] D. L. Sparks, Environmental Soil Chemistry, Academic Press, San Diego, Calif, USA, 2003.

[27] A. Violante, V. Cozzolino, L. Perelomov, A. G. Caporale, and M. Pigna, "Mobility and bioavailability of heavy metals and metalloids in soil environments," Journal of Soil Science and Plant Nutrition, vol. 10, no. 3, pp. 268-292, 2010.

[28] J. M. Dasch, "Measurement of dry deposition to surfaces in deciduous and pine canopies," Environmental Pollution, vol. 44, no. 4, pp. 261-277, 1987.

[29] Codex Alimentarius Commission (FAO/WHO), "Food additives and contaminants," Joint FAO/WHO Food Standards Programme, ALINORM 01/12A, 2001, 2001.

[30] D. Pavlíková, T. Macek, M. Macková, M. Surá, J. Száková, and P. Tlustoš, "The evaluation of cadmium, zinc and nickel accumulation ability of transgenic tobacco bearing different transgenes," Plant, Soil and Environment, vol. 50, no. 12, pp. 513517, 2004.

[31] S. H. Wani, "Phytoremediation, curing soil problems with crops," African Journal of Agricultural Research, vol. 7, no. 28, pp. 3991-4002, 2012. 

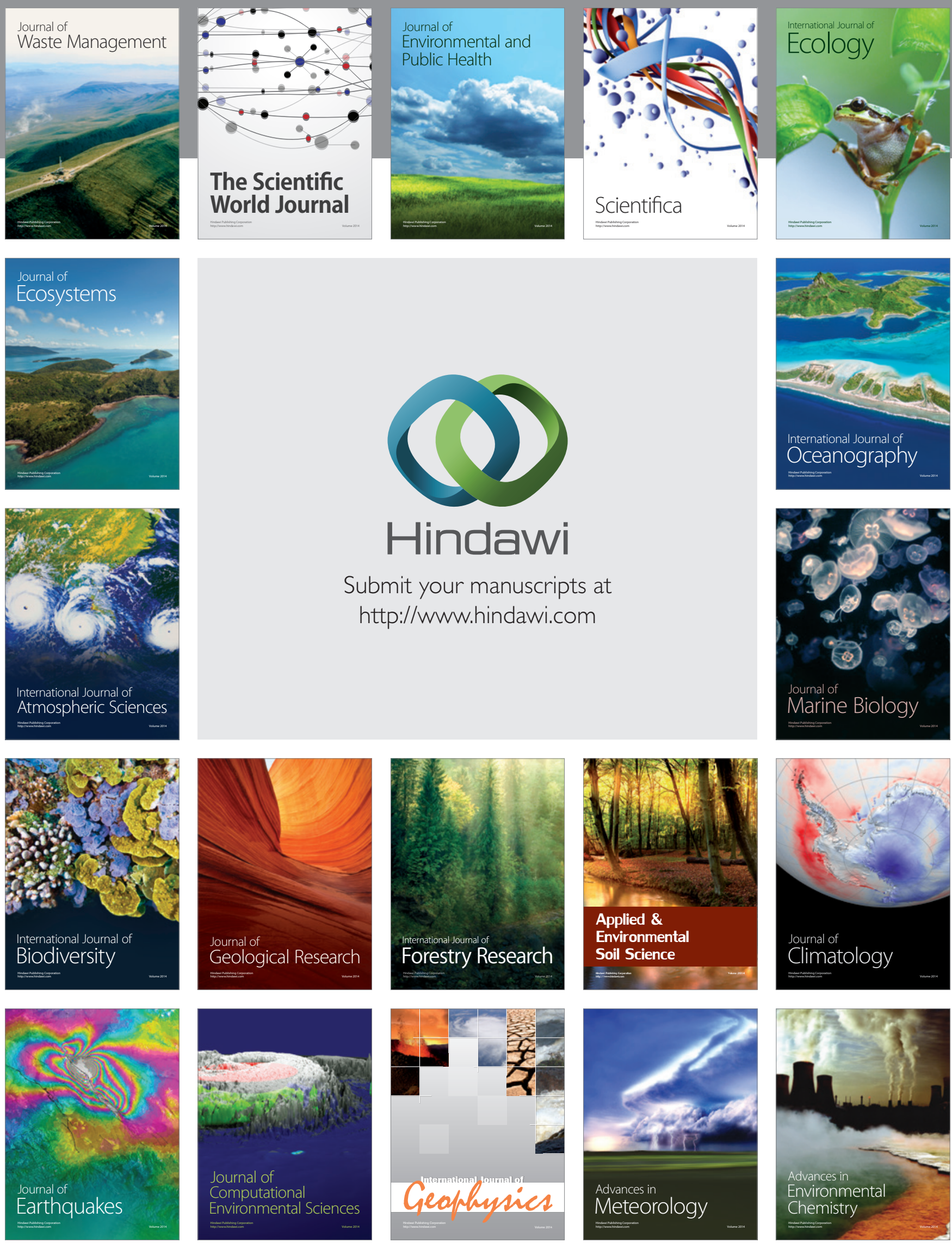